\title{
Suppression of Intersite Charge Transfer in Charge-Disproportionated Perovskite $\mathrm{YCu}_{3} \mathrm{Fe}_{4} \mathrm{O}_{12}$
}

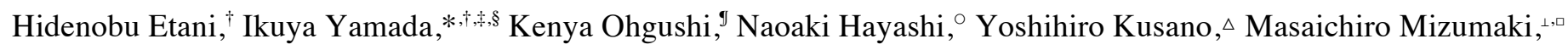
Jungeun Kim, ${ }^{\perp}$ Naruki Tsuji, ${ }^{\perp}$ Ryoji Takahashi,${ }^{\dagger}$ Norimasa Nishiyama, $, 4, \$$ Toru Inoue, ${ }^{\#}$ Tetsuo Irifune,,${ }^{\#}$ and Mikio Takano

${ }^{\dagger}$ Department of Chemistry, Graduate School of Science and Engineering, Ehime University, 2-5 Bunkyo-cho, Matsuyama, Ehime 790-8577, Japan

${ }^{\ddagger}$ Nanoscience and Nanotechnology Research Center, Osaka Prefecture University, 1-2 Gakuen-cho, Naka-ku, Sakai, Osaka 599-8570, Japan

${ }^{\S}$ PRESTO, Japan Science and Technology Agency (JST), Chiyoda-ku, Tokyo 102-0075, Japan

${ }^{\unlhd}$ Institute for Solid State Physics (ISSP), University of Tokyo, 5-1-5 Kashiwanoha, Kashiwa, Chiba 227-8581, Japan

${ }^{\circ}$ Micro/Nano Fabrication Hub, Center for the Promotion of Interdisciplinary Education and Research (C-PiER), Kyoto

University, Sakyo-ku, Kyoto 606-8501, Japan

$\triangle$ Department of Applied Arts and Design, Kurashiki University of Science and the Arts, 2640 Nishinoura, Tsurajima-cho, Kurashiki, Okayama 712-8505, Japan

${ }^{\perp}$ Japan Synchrotron Radiation Research Institute (JASRI), Sayo-cho, Sayo-gun, Hyogo 679-5198, Japan

${ }^{\square}$ Core Research for Evolutional Science and Technology (CREST), JST, 5 Sanbancho, Chiyoda-ku, Tokyo 102-0075, Japan

${ }^{\#}$ Geodynamics Research Center (GRC), Ehime University, 2-5 Bunkyo-cho, Matsuyama, Ehime 790-8577, Japan

${ }^{\diamond}$ Institute for Integrated Cell-Material Sciences (iCeMS), Kyoto University, Sakyo-ku, Kyoto 606-8501, Japan

*To whom correspondence should be addressed.

E-mail: i-yamada@21c.osakafu-u.ac.jp

Tel: +81-72-254-9817

${ }^{4}$ Current address: Deutsches Elektronen Synchrotron (DESY), 22607 Hamburg, Germany 


\section{ABSTRACT}

A novel iron perovskite $\mathrm{YCu}_{3} \mathrm{Fe}_{4} \mathrm{O}_{12}$ was synthesized under high pressure and high temperature of $15 \mathrm{GPa}$ and

1273 K. Synchrotron X-ray and electron diffraction measurements have demonstrated that this compound crystallizes in the cubic $A A^{\prime}{ }_{3} B_{4} \mathrm{O}_{12}$-type perovskite structure (space group $\operatorname{Im} \overline{3}$, No. 204) with a lattice constant of $a=7.30764(10) \AA$ at room temperature. $\mathrm{YCu}_{3} \mathrm{Fe}_{4} \mathrm{O}_{12}$ exhibits a charge disproportionation of $8 \mathrm{Fe}^{3.75+} \rightarrow 3 \mathrm{Fe}^{5+}+5 \mathrm{Fe}^{3+}$, a ferrimagnetic ordering, and a metal-semiconductor-like transition simultaneously at $250 \mathrm{~K}$, unlike the known isoelectronic compound $\mathrm{LaCu}_{3} \mathrm{Fe}_{4} \mathrm{O}_{12}$ that currently shows an intersite charge transfer of $3 \mathrm{Cu}^{2+}+4 \mathrm{Fe}^{3.75+} \rightarrow 3 \mathrm{Cu}^{3+}+4 \mathrm{Fe}^{3+}$, an antiferromagnetic ordering, and a metal-insulator transition at $393 \mathrm{~K}$. This finding suggests that intersite charge transfer is not the only way

of relieving the instability of the $\mathrm{Fe}^{3.75+}$ state in the $A^{3+} \mathrm{Cu}^{2+}{ }_{3} \mathrm{Fe}^{3.75+}{ }_{4} \mathrm{O}_{12}$ perovskites. Crystal structure analysis reveals that bond strain, rather than the charge account of the $A$-site alone, which is enhanced by large $A^{3+}$ ions, play an important role in determining which of intersite charge transfer or charge disproportionation is practical.

\section{INTRODUCTION}

Oxides containing $\mathrm{Fe}^{2+}$ and/or $\mathrm{Fe}^{3+}$, such as $\mathrm{FeO}, \mathrm{Fe}_{3} \mathrm{O}_{4}, \alpha-\mathrm{Fe}_{2} \mathrm{O}_{3}, \gamma-\mathrm{Fe}_{2} \mathrm{O}_{3}$, and $\mathrm{BaO} \cdot 6 \mathrm{Fe}_{2} \mathrm{O}_{3}$, have been extensively studied from both basic solid state chemistry and practical material science. It is said that FeO is a geoscientifically important substance, the metal-insulator transition at high pressures and high temperatures of which influences the autorotation of the earth, ${ }^{1}$ while the others mentioned above have been used practically utilized as coloring materials, catalysts, and magnetic materials. In contrast, oxides containing $\mathrm{Fe}^{4+}$ are much less explored, mainly because their synthesis requires strongly oxidizing atmosphere and also because important practical applications have not been 
known. However, we believe that it is of great interest to exploit new phases and new functionalities because $\mathrm{Fe}^{4+}$-oxides exhibit a variety of intriguing electronic phenomena that are not seen in $\mathrm{Fe}^{2+}$ - and $\mathrm{Fe}^{3+}$-oxides. $\mathrm{Fe}^{2+}-$ and $\mathrm{Fe}^{3+}$-oxides are all antiferromagnetic insulators in their ground states, but the most representative $\mathrm{Fe}^{4+}$-perovskite, $\mathrm{SrFe}^{4+} \mathrm{O}_{3}$, preserves metallic conductivity and cubic symmetry down to low temperature. ${ }^{2,3}$ This is surprising because $\mathrm{Fe}^{4+}\left(d_{\varepsilon}{ }^{3} d_{\gamma}{ }^{1}\right)$ is isoelectronic with $\mathrm{Mn}^{3+}$, which is known for its very strong preference for orbital ordering. The difference between $\mathrm{Mn}^{3+}$ and $\mathrm{Fe}^{4+}$ has been attributed to a significant decrease in charge transfer energy (energy for ligand-to-metal electron transfer), $\Delta_{\text {eff }}$, from $+1.8 \mathrm{eV}$ for $\mathrm{Mn}^{3+}$ to $-3 \mathrm{eV}$ for $\mathrm{Fe}^{4+} .4$ As typical examples of the specificity of $\mathrm{Fe}^{4+}$ oxides, we mention here the metallicity and helicoidal spin structure of $\mathrm{SrFeO}_{3},{ }^{2,5,6}$ the charge disproportionation of $2 \mathrm{Fe}^{4+} \rightarrow \mathrm{Fe}^{5+}+\mathrm{Fe}^{3+}$, or $2 \mathrm{Fe}^{3+} \underline{L} \rightarrow \mathrm{Fe}^{3+} \underline{L^{2}}+\mathrm{Fe}^{3+}$ ( $\underline{L}:$ ligand hole) according to the ligand hole picture, in $\mathrm{CaFeO}_{3},{ }^{7}$ and the ferromagnetism of $\mathrm{BaFeO}_{3}\left(3.5 \mu_{\mathrm{B}} / \mathrm{Fe}\right) .^{8}$ There are theoretical studies also that are improving electronic understanding of these oxides..$^{9-12}$ Recent synthetic exploration of new $\mathrm{Fe}^{4+}$ oxides has been extended to $A \mathrm{Cu}_{3} \mathrm{Fe}_{4} \mathrm{O}_{12}$-type perovskites $(A=\mathrm{Ca}, \mathrm{Sr}$, and La; see the crystal structure ${ }^{13}$ in Figure 1a). ${ }^{14-16}$ These complex metal oxide systems exhibit versatile structural and electronic properties. $\mathrm{CaCu}_{3} \mathrm{Fe}_{4} \mathrm{O}_{12}$ undergoes a charge disproportionation that features a rock salt-type $\mathrm{Fe}^{3+} / \mathrm{Fe}^{5+}$ charge ordering, a ferrimagnetic $\mathrm{Cu}^{2+} \downarrow \mathrm{Fe}^{5+} \uparrow \mathrm{Fe}^{3+} \uparrow$ ordering, and also a metal-semiconductor transition, which occur simultaneously at $210 \mathrm{~K} \cdot{ }^{14}$ In contrast, $\mathrm{LaCu}_{3} \mathrm{Fe}_{4} \mathrm{O}_{12}$ displays simultaneous transitions including an intersite charge transfer of $3 \mathrm{Cu}^{2+}+4 \mathrm{Fe}^{3.75+} \rightarrow 3 \mathrm{Cu}^{3+}+4 \mathrm{Fe}^{3+}$, an antiferromagnetic ordering of $\mathrm{Fe}^{3+}$-spins, and a metal-insulator transition at $393 \mathrm{~K} \cdot{ }^{16}$ The difference between the Ca- and La-based systems has been attributed to localization of ligand holes around the $\mathrm{Fe}$ - and $\mathrm{Cu}$-sites, respectively. ${ }^{17}$ However, the factor controlling the relative stability of the charge disproportionation and the intersite charge transfer remains unknown. 
We recently reported the synthesis and unexpected structural and electronic properties of a Sr-based analogue,

$\mathrm{SrCu}_{3} \mathrm{Fe}_{4} \mathrm{O}_{12}{ }^{15}$ This oxide displays a crossover-like, not a sharp transition-like, intersite charge transfer featuring a

negative thermal expansion between 170 and $270 \mathrm{~K}$, followed by a charge disproportionation with a relative abundance of

$\mathrm{Fe}^{5+}: \mathrm{Fe}^{3+}$ of $\sim 1: 4$. This is in stark contrast to the 1:1-type charge disproportionation in $\mathrm{CaCu}_{3} \mathrm{Fe}_{4} \mathrm{O}_{12}$, and the difference

was assigned to the increased bond strain caused by the replacement of $\mathrm{Ca}^{2+}$ ions by larger $\mathrm{Sr}^{2+}$ ions. This dependence on

ion size suggests that $A^{3+} \mathrm{Cu}_{3} \mathrm{Fe}_{4} \mathrm{O}_{12}$ may also exhibit significant dependence on the ion size of $A^{3+}$. Here, we report a novel

perovskite, $\mathrm{YCu}_{3} \mathrm{Fe}_{4} \mathrm{O}_{12}$, which contains small $\mathrm{Y}^{3+}$ ions (Shannon's ionic radius, $1.019 \AA$ ) instead of larger La ${ }^{3+}$ ones $(1.16$

$\AA$ ). ${ }^{18}$ As a result, $\mathrm{YCu}_{3} \mathrm{Fe}_{4} \mathrm{O}_{12}$ has been found to show a charge disproportionation of $8 \mathrm{Fe}^{3.75+} \rightarrow 3 \mathrm{Fe}^{5+}+5 \mathrm{Fe}^{3+}$, a

ferrimagnetic ordering, and a metal-semiconductor transition simultaneously at $250 \mathrm{~K}$. Moreover, the present structural

refinement revealed that bond strain, which is enhanced by large $A^{3+}$ cations, is a criterion controlling relative stability of

charge disproportionation and intersite charge transfer.

\section{EXPERIMENTAL SECTION}

A precursor was prepared by the polymerized complex method. ${ }^{19}$ Stoichiometric amounts of $\mathrm{Y}_{2} \mathrm{O}_{3}(99.99 \%)$,

$\mathrm{Cu}\left(\mathrm{NO}_{3}\right)_{2} \cdot 3 \mathrm{H}_{2} \mathrm{O}(99.9 \%)$, and $\mathrm{Fe}\left(\mathrm{NO}_{3}\right)_{3} \cdot 9 \mathrm{H}_{2} \mathrm{O}(99.9 \%)$ were dissolved in nitric acid, to which a five-fold excess of citric acid, and a one-fold excess of 1,2-ethanediol were added while stirring. The resulting solution was heated, while being

stirred, up to $573 \mathrm{~K}$ and kept there for $1 \mathrm{~h}$ to dryness. Subsequently, the dried powder was fired using a furnace at $673 \mathrm{~K}$

for $1 \mathrm{~h}$ and $948 \mathrm{~K}$ for $12 \mathrm{~h}$ in air with occasional grindings. The obtained precursor with a nominal chemical composition of $\mathrm{Y}^{3+} \mathrm{Cu}^{2+}{ }_{3} \mathrm{Fe}^{3+}{ }_{4} \mathrm{O}_{10.5}$ was mixed with an oxidizing agent $\mathrm{KClO}_{4}(99.9 \%)$ in a molar ratio of 2:1. Kawai-type high-pressure 
cell, in which an octahedral high-pressure medium is compressed by eight cubic WC anvils with truncated corners, was adopted in high-pressure synthesis experiments. The sample mixture was sealed off during the treatment in a platinum capsule with an inner diameter of $2.8 \mathrm{~mm}$ and a height of $4.0 \mathrm{~mm}$. The capsule was placed, together with a graphite furnace around it, into an octahedrally shaped $(\mathrm{Mg}, \mathrm{Co}) \mathrm{O}$ pressure medium, compressed to $15 \mathrm{GPa}$ using an high-pressure apparatus at GRC, Ehime University. The sample was subsequently heated to $1273 \mathrm{~K}$ in $20 \mathrm{~min}$, kept at this temperature for $30 \mathrm{~min}$, and quenched to room temperature. The pressure was released after the heat treatment. The obtained polycrystalline sample was washed several times with water and acetone. Sample pellets for electrical resistivity measurements were obtained by sintering the above prepared powder at $15 \mathrm{GPa}$ and $1273 \mathrm{~K}$ for 30 min when $\mathrm{KClO}_{4}$ powder was packed at the both ends of the platinum capsule.

We adopted synchrotron X-ray powder diffraction (SXRD) for structure refinement. High-energy and high-intensity synchrotron X-ray enables precise refinement of atomic positions of light elements such as oxygen and hydrogen. ${ }^{20-22}$ The SXRD experiments were performed at the BL02B2 beamline of SPring-8, Japan using samples contained in glass capillary tubes with an inner diameter of $0.2 \mathrm{~mm}$. The wavelength used was determined to be 0.49940 $\AA$ by using a $\mathrm{CeO}_{2}$ standard. Structure parameters were refined by Rietveld analysis using the program RIETAN-FP. ${ }^{23}$ Absorption correction was not considered in the refinement since the reduction in Bragg reflection intensity was estimated at less than $1 \%$ for the highest $2 \theta$ angle for Rietveld refinement. Electron diffraction (ED) patterns were collected at 300 and $110 \mathrm{~K}$ using a transmission electron microscope (JEOL JEM-2100F).

\footnotetext{
${ }^{57} \mathrm{Fe}$ Mössbauer measurements were performed in transmission geometry using ${ }^{57} \mathrm{Co} / \mathrm{Rh}$ as a radiation source
} and $\alpha$-Fe as a control for velocity calibration and isomer shift. Collected spectra were fitted computationally using the 
Lorentzian function. Magnetization measurements were conducted using a superconducting quantum interference device (SQUID, Quantum Design MPMS-XL) between 5 and $300 \mathrm{~K}$ under external fields of up to $50 \mathrm{kOe}$. Electrical resistivity was measured by the standard four-probe method using a Quantum Design PPMS. Soft X-ray absorption spectroscopy (XAS) and magnetic circular dichroism (MCD) for the $\mathrm{Cu} L_{2,3^{-}}$and $\mathrm{Fe} L_{2,3}$-edges were measured at $15 \mathrm{~K}$ in an external magnetic field of $19 \mathrm{kOe}$ by a total electron yield method at the BL25SU beamline of SPring-8.

\section{RESULTS AND DISCUSSION}

Well crystallized polycrystalline samples of $\mathrm{YCu}_{3} \mathrm{Fe}_{4} \mathrm{O}_{12}$ were successfully obtained at $15 \mathrm{GPa}$ and $1273 \mathrm{~K}$.

Homogeneous mixing of constituent elements in the starting powder by the use of the wet chemical method mentioned above proved to be crucially important to raise the sample quality, as was the case for $\mathrm{SrCu}_{3} \mathrm{Fe}_{4} \mathrm{O}_{12}$ also. ${ }^{15}$ By the use of $\mathrm{SXRD}, \mathrm{YCu}_{3} \mathrm{Fe}_{4} \mathrm{O}_{12}$ has been found to crystallize in the cubic $A A^{\prime}{ }_{3} B_{4} \mathrm{O}_{12}$-type perovskite structure with a lattice constant of $a=7.30764(10) \AA$ at $300 \mathrm{~K}$ (Figure 1a). The ED data measured at 295-300 K have shown that its space group is $\operatorname{Im} \overline{3}$ (No. 204) (see the inset of Figure 2a and Figure S1 in Supporting Information). However, small amounts of unknown phase(s) (presumably a few wt $\%$ ) were detected by SXRD, the reflections from which were excluded in the structure refinement. A stoichiometric model was used for the structure refinement for simplicity although the Mössbauer spectra indicated the presence of a very small amount (ca. 2 at\%) of Fe ions occupying the $A^{\prime}$-sites, as shown later. Table 1 lists the final results including lattice constant, structure parameters, reliability factors, and goodness-of-fit. The small values of the reliability factors and goodness-of-fit indicated that the refinement was successful. Selected bond lengths and angles, and bond valence sums $(\mathrm{BVS})^{24}$ are summarized in Table 2. The BVS for $\mathrm{Y}, \mathrm{Cu}$, and $\mathrm{Fe}$ are $+2.82,+2.05$, and 
+3.77 , respectively, at $300 \mathrm{~K},{ }^{25}$ suggesting that the appropriate ionic model at room temperature is $\mathrm{Y}^{3+} \mathrm{Cu}^{2+}{ }_{3} \mathrm{Fe}^{3.75+}{ }_{4} \mathrm{O}_{12}$.

Note that this electronic state differs from that of $\mathrm{La}^{3+} \mathrm{Cu}^{3+}{ }_{3} \mathrm{Fe}^{3+}{ }_{4} \mathrm{O}_{12}$ at room temperature. ${ }^{16}$

The microscopic state of the Fe ions was investigated by ${ }^{57} \mathrm{Fe}$ Mössbauer spectroscopy. Figure 3 shows the spectra measured at temperatures between 4 and $290 \mathrm{~K}$, and the hyperfine parameters obtained by fitting are presented in Table 3. The spectrum at $290 \mathrm{~K}$ has been found to contain two superimposed components with a relative abundance of 98:2. The principal component is the singlet from Fe ions located at $B$-sites $\left(B\right.$-Fe; isomer shift $\left.I S=0.16 \mathrm{~mm} \mathrm{~s}^{-1}\right)$. This $I S$ is comparable to that for the $\mathrm{Fe}^{4+}$ ions of $\mathrm{CaCu}_{3} \mathrm{Fe}_{4} \mathrm{O}_{12}$ at room temperature $\left(I S=0.15 \mathrm{~mm} \mathrm{~s}{ }^{-1}\right),{ }^{14}$ thus indicating that the valence state in $\mathrm{YCu}_{3} \mathrm{Fe}_{4} \mathrm{O}_{12}$ at room temperature is closer to +4 than to +3 . Together with the BVS results, it has been concluded that $\mathrm{Y}^{3+} \mathrm{Cu}^{2+}{ }_{3} \mathrm{Fe}^{3.75+}{ }_{4} \mathrm{O}_{12}$ is the proper picture. The other component, the doublet with $I S=0.41 \mathrm{~mm} \mathrm{~s}^{-1}$ and a large quadrupole splitting of $E_{q}=1.75 \mathrm{~mm} \mathrm{~s}^{-1}$, has been assigned to a small amount of $\mathrm{Fe}^{3+}$ at $A^{\prime}$-sites $\left(A^{\prime}\right.$ - $\left.\mathrm{Fe}\right)$ as also done for $\mathrm{CaCu}_{3} \mathrm{Fe}_{4} \mathrm{O}_{12} \cdot{ }^{14}$ On cooling, the principal component began to be magnetically split below $\sim 230 \mathrm{~K}$. It is evident that the 4K-spectrum consists of three superimposed components: $\mathrm{Fe}^{5+}(36 \%), \mathrm{Fe}^{3+}(1)(52 \%)$, and $\mathrm{Fe}^{3+}(2)(12 \%)$. The relative abundance of $\mathrm{Fe}^{5+}: \mathrm{Fe}^{3+}(1,2) \fallingdotseq \sim 3: 5$ demonstrates a charge disproportionation of $8 \mathrm{Fe}^{3.75+} \rightarrow 3 \mathrm{Fe}^{5+}+5 \mathrm{Fe}^{3+}$, where the splitting of the $\mathrm{Fe}^{3+}$ component into $\mathrm{Fe}^{3+}(1)$ and $\mathrm{Fe}^{3+}(2)$ has been considered to result from their different environments, as discussed later. This observation reveals that intersite charge transfer is not the only way to resolve the instability of $\mathrm{Fe}^{3.75+}$ ions for this type of perovskite, although previous reports suggested that the $d$ electron count tuned by $A$-site ions, $\mathrm{Fe}^{4+}$ for $A^{2+}$ and $\mathrm{Fe}^{3.75+}$ for $A^{3+}$, determines the dominance of charge disproportionation or intersite charge transfer. ${ }^{27,28,30}$

Whether the $\mathrm{Fe}^{3+}$ and $\mathrm{Fe}^{5+}$ ions are ordered or not was investigated using $\mathrm{ED}$ and SXRD. The temperature dependence of the lattice constant, $a$, showed a slight but well-defined decrease in the vicinity of $250 \mathrm{~K}$ (Figure $2 \mathrm{c}$ ), and 
the ED data obtained at $110-122 \mathrm{~K}$ revealed the appearance of the superllatice reflections such as 111 and $2 \overline{4} 1$ (the inset of Figure $2 \mathrm{~b}$ and Figure $\mathrm{S} 1$ in Supporting Information) that indicated a change in lattice symmetry. These are both similar to what happen in the Ca-analogue undergoing the charge disproportionation to $\mathrm{Ca}^{2+} \mathrm{Cu}^{2+}{ }_{3} \mathrm{Fe}^{3+}{ }_{2} \mathrm{Fe}^{5+}{ }_{2} \mathrm{O}_{12}$ (space group $P n \overline{3}$, No. 201). ${ }^{14}$ Therefore, we used an initial model of rock salt-type charge ordering (space group $P n \overline{3}$, No. 201) for the structural refinement using the SXRD data at $100 \mathrm{~K}$. As a result, we identified a pair of Fe sites featuring different Fe-O bond lengths, 1.971(11) and 1.906(11) A, and obtained reasonable BVS values for all the atoms (see Table 2). Thus, we conclude that $\mathrm{YCu}_{3} \mathrm{Fe}_{4} \mathrm{O}_{12}$ transforms to a charge-disproportionated, charge-ordered phase below $250 \mathrm{~K}$, similarly to $\mathrm{CaCu}_{3} \mathrm{Fe}_{4} \mathrm{O}_{12}$. We should note here that the charge ordering is not hindered by the deviation in abundance from the well-known one of $\mathrm{Fe}^{5+}: \mathrm{Fe}^{3+}=1: 1$. Most probably, the two distinct crystallographic Fe sites, $4 b$ and $4 c$, are occupied by $\mathrm{Fe}^{3+}$ and $\left({ }^{3} / \mathrm{Fe}^{5+}+{ }_{1} / \mathrm{Fe}^{3+}\right)$, respectively (see the crystal structure in Figure $1 \mathrm{~b}$ ). The $\mathrm{Fe}^{3+}$ ions located at the two different sites are distinguished as $\mathrm{Fe}^{3+}(1)$ at $4 b$ sites and $\mathrm{Fe}^{3+}(2)$ at $4 c$ sites. The $\mathrm{Fe}^{3+}(2)$ ions are presumably randomly distributed at $4 c$ sites because there is no indication of any other type of charge ordering at $4 c$ sites in ED data and superlattice reflection in SXRD pattern (see Figure 2b, 2d and Figure S1 in Supporting Information). The difference in the hyperfine parameters of $\mathrm{Fe}^{3+}(1)$ and $\mathrm{Fe}^{3+}(2)$ can be rationalized based on their magnetization data, as discussed below. Magnetic susceptibility data obtained for $\mathrm{YCu}_{3} \mathrm{Fe}_{4} \mathrm{O}_{12}$ displayed a ferromagnetic transition at $250 \mathrm{~K}$ (Figure 4a). The ferromagnetic transition temperature of $\mathrm{YCu}_{3} \mathrm{Fe}_{4} \mathrm{O}_{12}$ is slightly higher than that of $\mathrm{CaCu}_{3} \mathrm{Fe}_{4} \mathrm{O}_{12}(210 \mathrm{~K})$. The isothermal magnetization curve at $5 \mathrm{~K}$ indicates that the experimental saturation magnetization $\left(M_{\mathrm{s}}\right)$ is approximately $7.6 \mu_{\mathrm{B}}$ per formula unit (Figure $\left.4 \mathrm{~b}\right)$. This value is close to that of $\mathrm{CaCu}_{3} \mathrm{Fe}_{4} \mathrm{O}_{12}\left(M_{\mathrm{s}}=9.7 \mu_{\mathrm{B}}\right),{ }^{14}$ implying ferrimagnetic ordering of $\mathrm{Cu}$ and $\mathrm{Fe}$ in $\mathrm{YCu}_{3} \mathrm{Fe}_{4} \mathrm{O}_{12}$. Antiparallel alignment of $\mathrm{Cu}$ and $\mathrm{Fe}$ spins was confirmed by $\mathrm{MCD}$ spectra at $15 \mathrm{~K}$. 
XAS and MCD spectra obtained for $\mathrm{YCu}_{3} \mathrm{Fe}_{4} \mathrm{O}_{12}$ at $15 \mathrm{~K}$ are presented in Figure 5. The $\mathrm{Cu} L_{2,3}$-edge spectra of $\mathrm{YCu}_{3} \mathrm{Fe}_{4} \mathrm{O}_{12}$ are similar to those of $\mathrm{CaCu}_{3} \mathrm{Fe}_{4} \mathrm{O}_{12},{ }^{26}$ revealing that the valence state of $\mathrm{Cu}$ remains divalent at low temperature, and intersite charge transfer does not occur between $\mathrm{Cu}$ and $\mathrm{Fe}$ in $\mathrm{YCu}_{3} \mathrm{Fe}_{4} \mathrm{O}_{12}$. The MCD intensities of the Fe $L_{2}$-edge $\left(L_{3}\right.$-edge) are positive (negative) whereas those of the $\mathrm{Cu} L_{2}$-edge $\left(L_{3}\right.$-edge) are negative (positive). This reveals that the net magnetic coupling between $\mathrm{Cu}$ and $\mathrm{Fe}$ spins is considered antiferromagnetic. Compared with $\mathrm{CaCu}_{3} \mathrm{Fe}_{4} \mathrm{O}_{12},{ }^{14}$ the slightly smaller $M_{\mathrm{s}}$ of $\mathrm{YCu}_{3} \mathrm{Fe}_{4} \mathrm{O}_{12}$ is attributed to the antiparallel alignment of some of the $\mathrm{Fe}^{3+}$ ions. This is because antiferromagnetic interaction is probably dominant between $\mathrm{Fe}^{3+}(1)$ and $\mathrm{Fe}^{3+}(2)$ in $\mathrm{YCu}_{3} \mathrm{Fe}_{4} \mathrm{O}_{12}$, as in the case of the $\mathrm{Fe}^{3+}$ spins of the antiferromagnetic $\mathrm{La}^{3+} \mathrm{Cu}^{3+}{ }_{3} \mathrm{Fe}^{3+}{ }_{4} \mathrm{O}_{12}$ phase. ${ }^{27}$ Instead, the ferromagnetic superexchange interaction dominates in $\mathrm{Fe}^{3+}(1)-\mathrm{O}-\mathrm{Fe}^{5+}$ bonds. Therefore, the magnetic ordered state of $\mathrm{YCu}_{3} \mathrm{Fe}_{4} \mathrm{O}_{12}$ is described as $\mathrm{Cu}^{2+} \downarrow-\mathrm{Fe}^{5+} \uparrow-\mathrm{Fe}^{3+}(1) \uparrow-\mathrm{Fe}^{3+}(2) \downarrow$. A schematic diagram of the magnetic interactions is depicted in Figure 6. This model calculates a $M_{\mathrm{s}}$ of $9 \mu_{\mathrm{B}}$ for $\mathrm{YCu}_{3} \mathrm{Fe}_{4} \mathrm{O}_{12}$, which is slightly larger than the experimental value. This difference is probably derived from the local disturbance of the magnetic ordering by $A^{\prime}-\mathrm{Fe}^{3+}$, which was also observed for $\mathrm{CaCu}_{3} \mathrm{Fe}_{4} \mathrm{O}_{12} \cdot{ }^{14}$ Mössbauer spectra provide further evidence for the above magnetic structure. The hyperfine parameters of $\mathrm{Fe}^{5+}$ and $\mathrm{Fe}^{3+}(1)$ at $4 \mathrm{~K}$ (see Table 3) are similar to those of ferrimagnetic $\mathrm{CaCu}_{3} \mathrm{Fe}_{4} \mathrm{O}_{12}\left(I S=0.05 \mathrm{~mm} \mathrm{~s}^{-1}, H F=227 \mathrm{kOe}\right.$ for $\mathrm{Fe}^{5+}$ and $I S=0.39 \mathrm{~mm} \mathrm{~s}^{-1}, H F=417 \mathrm{kOe}$ for $\mathrm{Fe}^{3+}$, respectively), ${ }^{14}$ whereas the hyperfine parameters of $\mathrm{Fe}^{3+}(2)$ at $4 \mathrm{~K}$ are $^{3}$ similar to those of antiferromagnetic $\mathrm{La}^{3+} \mathrm{Cu}^{3+}{ }_{3} \mathrm{Fe}^{3+}{ }_{4} \mathrm{O}_{12}\left(I S \approx 0.47 \mathrm{~mm} \mathrm{~s}^{-1}\right.$ and $\left.H F \approx 520 \mathrm{kOe}\right){ }^{27}$ This finding confirms that the charge-disproportionated $\mathrm{YCu}_{3} \mathrm{Fe}_{4} \mathrm{O}_{12}$ phase retains rock salt-type charge ordering of $\mathrm{Fe}^{3+}$ and $\mathrm{Fe}^{5+}$, in which some $\mathrm{Fe}^{5+}$ sites are substituted by excess $\mathrm{Fe}^{3+}$ ions.

Electrical resistivity measurements also indicated that an electronic phase transition occurred below $250 \mathrm{~K}$. The 
electrical resistivity is almost temperature-independent above $250 \mathrm{~K}$, probably because of the $\mathrm{Fe}^{3.75+}$ state exhibits metallic transport, followed by a semiconductor-like small increase slightly below this temperature, as shown in Figure 4c. This behavior is similar to the metal-semiconductor transition of $\mathrm{CaCu}_{3} \mathrm{Fe}_{4} \mathrm{O}_{12} \cdot{ }^{14}$ The reasons for almost constant electrical resistivity below $150 \mathrm{~K}$ and its increase below $50 \mathrm{~K}$ are not clear at this point, but similar behavior was also observed for $\mathrm{CaCu}_{3} \mathrm{Fe}_{4} \mathrm{O}_{12} \cdot{ }^{14}$ Since the Mössbauer hyperfine parameters are almost identical at 4 and $100 \mathrm{~K}$ (see Table 3), the increase below $50 \mathrm{~K}$ is not probably due to the change of electronic state. In-depth study with a high quality single crystal is needed for revealing the electrical transport properties, but this is beyond the subject of this study.

The above experimental results reveal that the instability of the high valence $\mathrm{Fe}^{3.75+}$ state in $\mathrm{YCu}_{3} \mathrm{Fe}_{4} \mathrm{O}_{12}$ is resolved by charge disproportionation in a manner similar to that of $\mathrm{CaCu}_{3} \mathrm{Fe}_{4} \mathrm{O}_{12},{ }^{14}$ not by intersite charge transfer as observed in $\mathrm{LaCu}_{3} \mathrm{Fe}_{4} \mathrm{O}_{12}{ }^{16}$ This leads to the question of what determines the electronic states in $A^{3+} \mathrm{Cu}_{3} \mathrm{Fe}_{4} \mathrm{O}_{12}$ perovskites at low temperature. It has been reported that $A^{3+} \mathrm{Cu}_{3} \mathrm{Fe}_{4} \mathrm{O}_{12}$ perovskites $(A=\mathrm{La}, \mathrm{Bi})$ exhibit an intersite charge transfer transition below $\sim 400 \mathrm{~K}$ and exhibit no signs of charge disproportionation. ${ }^{16,29}$ Therefore, the $\mathrm{Fe}^{3.75+}$ valence states of $A^{3+} \mathrm{Cu}_{3} \mathrm{Fe}_{4} \mathrm{O}_{12}$ perovskites have previously been considered to be relieved only by intersite charge transfer. It has been suggested that charge disproportionation to form a charge-ordered structure with some $\mathrm{Fe}^{3+}$ incorporated at $\mathrm{Fe}^{5+}$ sites would destabilize the lattice, causing charge disproportionation to be disfavored.$^{27,28,30}$ However, our experimental results for $\mathrm{YCu}_{3} \mathrm{Fe}_{4} \mathrm{O}_{12}$ reveal that the valence state of $A$-ion $\left(A^{2+}\right.$ or $\left.A^{3+}\right)$ in $A \mathrm{Cu}_{3} \mathrm{Fe}_{4} \mathrm{O}_{12}$ perovskites does not solely determine the type of electronic phase transition (charge disproportionation or intersite charge transfer). Based on the results of structure refinement, we next consider the factors that determine whether charge disproportionation or intersite charge transfer is dominant in $A^{3+} \mathrm{Cu}_{3}^{2+} \mathrm{Fe}^{3.75+}{ }_{4} \mathrm{O}_{12}$ perovskites. 
To evaluate metal-oxygen bonding states in the high temperature $A^{3+} \mathrm{Cu}^{2+}{ }_{3} \mathrm{Fe}^{3.75+}{ }_{4} \mathrm{O}_{12}$ phase $(A=\mathrm{La}, \mathrm{Y})$, bond discrepancy factors, ${ }^{31} d_{\mathrm{M}}=B V S(\mathrm{M})-V_{\mathrm{M}}$, where $B V S(\mathrm{M})$ is the bond valence sum of $\mathrm{M}$ ion calculated from the structure parameters and $V_{\mathrm{M}}$ is the nominal valence of $\mathrm{M}$ ion estimated from the ionic model, were calculated from the crystal structure refinement results at $450 \mathrm{~K}$. Values of $d_{\mathrm{La}}=+0.53, d_{\mathrm{Cu}}=+0.06$, and $d_{\mathrm{Fe}}=-0.31$ were calculated for $\mathrm{LaCu}_{3} \mathrm{Fe}_{4} \mathrm{O}_{12}{ }^{16}$ and $d_{\mathrm{Y}}=-0.19, d_{\mathrm{Cu}}=+0.04$, and $d_{\mathrm{Fe}}=-0.04$ were determined for $\mathrm{YCu}_{3} \mathrm{Fe}_{4} \mathrm{O}_{12}$, in which positive and negative $d_{\mathrm{M}}$ indicate overbonding and underbonding for the relevant bonds, respectively. The very small $d_{\mathrm{Cu}}$ for both compounds indicate that the $\mathrm{Cu}-\mathrm{O}$ bond matches the divalent $\mathrm{Cu}$ ions. In contrast, $d_{\mathrm{M}}$ of the $A$-ions differ significantly. The large positive $d_{\mathrm{La}}$ value implies overbonding and strong compression of the La-O bond, which is attributed to the unit cell volume being restricted by the rigid $\mathrm{FeO}_{6}$ octahedral network. ${ }^{32}$ In contrast, the large negative $d_{\mathrm{Fe}}$ value of $\mathrm{LaCu}_{3} \mathrm{Fe}_{4} \mathrm{O}_{12}$ indicates that the $\mathrm{Fe}-\mathrm{O}$ bond is forcibly stretched by the relatively large La ion, resulting in the underbonding. These over- and under-bonding in the high-temperature $\mathrm{LaCu}_{3} \mathrm{Fe}_{4} \mathrm{O}_{12}$ phase may be the driving force for intersite charge transfer. This is because these unstable bondings are resolved by intersite charge transfer and thus the considerable deviations of $d_{\mathrm{La}}$ and $d_{\mathrm{Fe}}$ from zero are relaxed, although small deviation of $d_{\mathrm{Cu}}$ is retained $\left(d_{\mathrm{La}}=+0.40, d_{\mathrm{Cu}}=\right.$ -0.10 , and $d_{\mathrm{Fe}}=+0.05$ for the $\mathrm{La}^{3+} \mathrm{Cu}^{3+}{ }_{3} \mathrm{Fe}^{3+}{ }_{4} \mathrm{O}_{12}$ phase at $\left.300 \mathrm{~K}\right) \cdot{ }^{16}$ In contrast, because both $d_{\mathrm{Y}}$ and $d_{\mathrm{Fe}}$ are very small negative values in $\mathrm{YCu}_{3} \mathrm{Fe}_{4} \mathrm{O}_{12}$ at $450 \mathrm{~K}$, intersite charge transfer is not necessarily dominant. The instability of the $\mathrm{Fe}^{3.75+}$ ion of $\mathrm{YCu}_{3} \mathrm{Fe}_{4} \mathrm{O}_{12}$ is thus resolved by charge disproportionation, like $\mathrm{Fe}^{4+}$ in $\mathrm{CaFeO}_{3}$ and $\mathrm{CaCu}_{3} \mathrm{Fe}_{4} \mathrm{O}_{12}{ }^{7.14}$ It is likely that $\angle B-\mathrm{O}-B$ bond angles, which tune the electronic structures in simple $A B \mathrm{O}_{3}$ perovskites, substantially influence such structural and electronic phase transitions in $A A_{3}^{\prime} B_{4} \mathrm{O}_{12}$-type perovskites. However, this is not the case for $A^{3+} \mathrm{Cu}_{3}^{2+} \mathrm{Fe}^{3.75+}{ }_{4} \mathrm{O}_{12}$ perovskites because there is no significant difference in $\angle \mathrm{Fe}-\mathrm{O}-\mathrm{Fe}$ bond angles (approximately $139^{\circ}$ 
for both $\mathrm{LaCu}_{3} \mathrm{Fe}_{4} \mathrm{O}_{12}$ and $\mathrm{YCu}_{3} \mathrm{Fe}_{4} \mathrm{O}_{12}$ at $\left.450 \mathrm{~K}\right)$.

Figure 7 shows a diagram of the electronic states of $A \mathrm{Cu}_{3} \mathrm{Fe}_{4} \mathrm{O}_{12}\left(A=\mathrm{Ca}^{2+}, \mathrm{Sr}^{2+}, \mathrm{Y}^{3+}\right.$, and $\left.\mathrm{La}^{3+}\right)$ perovskites at

low temperature. In those containing smaller $A$-site ions $\left(\mathrm{Ca}^{2+}\right.$ and $\left.\mathrm{Y}^{3+}\right)$, charge disproportionation is dominant, whereas intersite charge transfer (crossover-like or phase transition) predominantly occurs in those with larger $A$-site ions $\left(\mathrm{Sr}^{2+}\right.$ or

$\mathrm{La}^{3+}$ ). This is because strong bond strains, which are represented as over- and under-bonding, are introduced in perovskites with larger $A$-site ions. This system is a remarkable example demonstrating that bond strain plays a crucial role in determining the type of structural and electronic transformation.

\section{CONCLUSIONS}

A novel iron perovskite $\mathrm{YCu}_{3} \mathrm{Fe}_{4} \mathrm{O}_{12}$ was synthesized under high pressure and high temperature conditions. In this compound, instability of the high valence $\mathrm{Fe}^{3.75+}$ ion is relieved by charge disproportionation rather than intersite charge transfer, leading to charge ordering and ferrimagnetic ordering at low temperature. Together with electronic and spectroscopic measurements, crystal structure refinement revealed that bond strain aids in determining the type of electronic phase transition (intersite charge transfer or charge disproportionation) rather than just the valence state of $A$-site ions.

\section{ACKNOWLEDGEMENTS}

Synchrotron radiation experiments were performed at SPring-8 under the Priority Nanotechnology Support Program administered by JASRI (Proposal Nos. 2010B1707, 2011A1047, 2012A1002, and 2012B1171). This work was 
partly performed using the facilities of ISSP.

\section{AUTHOR INFORMATION}

\section{Corresponding Author}

i-yamada@21c.osakafu-u.ac.jp

Present Address

${ }^{\star}$ Deutsches Elektronen Synchrotron (DESY), 22607 Hamburg, Germany

\section{ASSOCIATED CONTENT}

Supporting Information. Electron diffraction patterns and crystallographic data (CIF) for $\mathrm{YCu}_{3} \mathrm{Fe}_{4} \mathrm{O}_{12}$. This material is available free of charge via the Internet at http://pubs.acs.org.

\section{REFERENCES}

(1) Ohta, K.; Cohen, R. E.; Hirose, K.; Haule, K.; Shimizu, K.; Ohishi Y. Phys. Rev. Lett. 2012, 108, 026403.

(2) MacChesney, J. B.; Sherwood, R. C.; Potter, J. F., J. Chem. Phys. 1965, 43, 1907-1913.

(3) Takeda, T.; Kanno, R.; Kawamoto, Y.; Takano, M.; Kawasaki, S.; Kamiyama, T.; Izumi, F., Solid State Sci. 2000, 2 , $673-687$.

(4) (a) Bocquet, A. E.; Fujimori, A.; Mizokawa, T.; Saitoh, T.; Namatame, H.; Suga, S.; Kimizuka, N.; Takeda, Y.; Takano, M., Phys. Rev. B 1992, 45, 1561-1570; (b) Bocquet, A. E.; Mizokawa, T.; Saitoh, T.; Namatame, H.; Fujimori, A., Phys. Rev. B 1992, 46, 3771-3784.

(5) Takeda, T.; Yamaguchi, Y.; Watanabe, N., J. Phys. Soc. Jpn. 1972, 33, 967-969.

(6) Takeda, T.; Komura, S.; Watanabe, N., Ferrites: Proc. ICF3, Kyoto 1980, 385-388. 
(7) Takano, M.; Nakanishi, N.; Takeda, Y.; Naka, S.; Takada, T., Mater. Res. Bull. 1977, 12, 923-928.

(8) Hayashi, N.; Yamamoto, T.; Kageyama, H.; Nishi, M.; Watanabe, Y.; Kawakami, T.; Matsushita, Y.; Fujimori, A.; Takano, M., Angew. Chem. Int. Ed. 2011, 50, 12547-12550.

(9) Kawakami, T.; Nasu, S., J. Phys.: Cond. Matter. 2005, 17, 789-793.

(10) Ishiwata, S.; Tokunaga, M.; Kaneko, Y.; Okuyama, D.; Tokunaga, Y.; Wakimoto, S.; Kakurai, K.; Arima, T.; Taguchi, Y.; Tokura, Y., Phys. Rev. B 2011, 84, 054427.

(11) Mostovoy, M., Phys. Rev. Lett. 2005, 94, 137205.

(12) Li, Z.; Laskowski, R.; Iitaka, T.; Tohyama, T., Phys. Rev. B 2012, 85, 134419.

(13) The crystal structure was drawn using the program VESTA: Momma, K.; Izumi, F., J. Appl. Crystallogr. 2008, 41, $653-658$.

(14) Yamada, I.; Takata, K.; Hayashi, N.; Shinohara, S.; Azuma, M.; Mori, S.; Muranaka, S.; Shimakawa, Y.; Takano, M., Angew. Chem. Int. Ed. 2008, 47, 7032-7035.

(15) Yamada, I.; Tsuchida, K.; Ohgushi, K.; Hayashi, N.; Kim, J.; Tsuji, N.; Takahashi, R.; Matsushita, M.; Nishiyama, N.; Inoue, T.; Irifune, T.; Kato, K.; Takata, M.; Takano, M., Angew. Chem. Int. Ed. 2011, 50, 6579-6582.

(16) Long, Y. W.; Hayashi, N.; Saito, T.; Azuma, M.; Muranaka, S.; Shimakawa, Y., Nature 2009, 458, 60-63.

(17) Chen, W.; Saito, T.; Hayashi, N.; Takano, M.; Shimakawa, Y., Sci.Rep. 2012, 449, 2.

(18) Shannon, R. D., Acta Crystallogr. Sect. A 1976, 32, 751-767.

(19) Kakihana, M., J. Sol-gel Sci. Technol. 1996, 6, 7-55.

(20) Kubota, Y.; Takata, M.; Matsuda, R.; Kitaura, R.; Kitagawa, S.; Kato, K.; Sakata, M.; Kobayashi, T. C. Angew. Chem. Int. Ed. 2005, 44, 920-923.

(21) Kuroiwa, Y.; Aoyagi, S.; Sawada, A. Phys. Rev. Lett. 2001, 87, 217601.

(22) Aoyagi, S.; Kuroiwa, Y.; Sawada, A.; Tanaka, H.; Harada, J.; Nishibori, E.; Takata, M.; Sakata, M. J. Phys. Soc. Jpn. 2002, 71, 2353-2356.

(23) Izumi, F.; Momma, K., Solid State Phenom. 2007, 130, 15-20.

(24) Brown, I. D.; Altermatt, D., Acta Crystallogr. Sect. B 1985, 41, 244-247. 
(25) (a) The BVS were calculated using the following parameters: $b_{0}=0.37$ for all atoms, $r_{0}=2.014$ for $\mathrm{Y}^{3+}, r_{0}=1.649$ for $\mathrm{Cu}^{2+}, r_{0}=1.772$ for $\mathrm{Fe}^{3.75+}, r_{0}=1.751$ for $\mathrm{Fe}^{3+}$, and $r_{0}=1.772$ for $\mathrm{Fe}^{3.75+}$. (b) Woodward, P. M.; Cox, D. E.; Moshopoulou, E.; Sleight, A. W.; Morimoto, S., Phys. Rev. B 2002, 62, 844-855. (c) Kanowitz, S. M.; Palenik, G. J., Inorg. Chem. 1998, 37, 2086-2088.

(26) Mizumaki, M.; Chen, W. T.; Saito, T.; Yamada, I.; Attfield, J. P.; Shimakawa, Y., Phys. Rev. B 2011, 84, 4.

(27) Chen, W.; Long, Y. W.; Saito, T.; Attfield, J. P.; Shimakawa, Y., J. Mater. Chem. 2010, 20, 7282-7286.

(28) Long, Y.; Shimakawa, Y., New J. Phys. 2010, 12, 063029.

(29) Long, Y.; Saito, T.; Tohyama, T.; Oka, K.; Azuma, M.; Shimakawa, Y., Inorg. Chem. 2009, 48, 8489-8492.

(30) Shimakawa, Y.; Takano, M., Z. Anorg. Allg. Chem. 2009, 635, 1882-1889.

(31) Brown, I. D., Chem. Rev. 2009, 109, 6858-6919.

(32) The lattice constant $a$ depends only on the Fe-related parameters, $d_{\mathrm{Fe}-\mathrm{O}}(\mathrm{Fe}-\mathrm{O}$ bond length $)$ and $\Psi(\angle \mathrm{Fe}-\mathrm{O}-\mathrm{Fe}$ bond angle); $a=4 d_{\mathrm{Fe}-\mathrm{O}} \sin (\Psi / 2)$. 
Table 1. Refined Structure Parameters for $\mathrm{YCu}_{3} \mathrm{Fe}_{4} \mathrm{O}_{12}$ at 100,300 , and $450 \mathrm{~K}{ }^{a}$

\begin{tabular}{|c|c|c|c|}
\hline Temperature / K & 100 & 300 & 450 \\
\hline Space group & $\operatorname{Pn} \overline{3}$ & $\operatorname{Im} \overline{3}$ & $\operatorname{Im} \overline{3}$ \\
\hline$a / \AA$ & $7.29160(11)$ & $7.30764(10)$ & $7.32265(13)$ \\
\hline$x(\mathrm{O})$ & $0.2452(16)$ & $0.3018(3)$ & $0.3017(3)$ \\
\hline$y(\mathrm{O})$ & $0.4256(4)$ & $0.1751(3)$ & $0.1741(4)$ \\
\hline$z(\mathrm{O})$ & $0.5515(3)$ & - & - \\
\hline$U_{\text {iso }}(\mathrm{Y}) \times 1000 / \AA^{2}$ & $1.9(5)$ & $4.0(5)$ & $6.8(6)$ \\
\hline$U_{\text {iso }}(\mathrm{Cu}) \times 1000 / \AA^{2}$ & $2.8(3)$ & $5.0(3)$ & $7.5(3)$ \\
\hline$U_{\text {iso }}(\mathrm{Fe} 1) \times 1000 / \AA^{2}$ & $1.0(2)^{b}$ & $2.3(2)$ & $4.0(2)$ \\
\hline$U_{\text {iso }}(\mathrm{Fe} 2) \times 1000 / \AA^{2}$ & $1.0(2)^{b}$ & - & - \\
\hline$U_{\text {iso }}(\mathrm{O}) \times 1000 / \AA^{2}$ & $1.5(7)$ & $4.0(6)$ & $6.8(7)$ \\
\hline$R_{\mathrm{wp}}(\%)$ & 3.202 & 2.859 & 3.230 \\
\hline$R_{\mathrm{B}}(\%)$ & 0.851 & 0.515 & 1.321 \\
\hline goodness-of-fit & 0.836 & 0.763 & 0.880 \\
\hline
\end{tabular}

${ }^{a}$ Space group: $\operatorname{Im} \overline{3}$ (No.204); atomic sites: Y $2 a(0,0,0), \mathrm{Cu} 6 b(0,1 / 2,1 / 2), \mathrm{Fe} 18 c(1 / 4,1 / 4,1 / 4), \mathrm{O} 24 g(x, y, 0)$; Space group: $\operatorname{Pn} \overline{3}$ (No.201); atomic sites: Y $2 a(1 / 4,1 / 4,1 / 4), \mathrm{Cu} 6 d(1 / 4,3 / 4,3 / 4), \mathrm{Fe} 14 b(0,0,0), \mathrm{Fe} 24 c(1 / 2,1 / 2,1 / 2), \mathrm{O} 24 h(x, y$, $z)$; The occupancy factor $g$ for all sites was fixed at unity.

${ }^{b}$ The following constraint was adopted: $U_{\text {iso }}(\mathrm{Fe} 1)=U_{\text {iso }}(\mathrm{Fe} 2)$. 
Table 2. Selected Bond Lengths, Angles, and BVS for Metal Ions in $\mathrm{YCu}_{3} \mathrm{Fe}_{4} \mathrm{O}_{12}$ at 100, 300, and $450 \mathrm{~K}$.

\begin{tabular}{llll}
\hline Temperature / K & 100 & 300 & 450 \\
\hline $\mathrm{Y}-\mathrm{O}(\times 12) / \AA$ & $2.544(3)$ & $2.550(3)$ & $2.551(3)$ \\
$\mathrm{Cu}-\mathrm{O}(\times 4) / \AA$ & $1.933(2)$ & $2.781(3)$ & $2.794(3)$ \\
$\mathrm{Cu}-\mathrm{O}(\times 4) / \AA$ & $2.773(3)$ & $1.9444(6)$ & $1.9503(7)$ \\
$\mathrm{Fe} 1-\mathrm{O}(\times 6) / \AA$ & $1.971(11)$ & - & - \\
$\mathrm{Fe} 2-\mathrm{O}(\times 6) / \AA$ & $1.906(11)$ & $140.0(2)$ & $139.7(2)$ \\
$\mathrm{Fe}-\mathrm{O}-\mathrm{Fe} /{ }^{\circ}$ & $140.2(2)$ & 2.82 & 2.81 \\
$\mathrm{BVS}(\mathrm{Y})$ & 2.86 & 2.05 & 2.04 \\
$\mathrm{BVS}(\mathrm{Cu})$ & 2.05 & 3.77 & 3.71 \\
$\mathrm{BVS}(\mathrm{Fe} 1)$ & $3.31^{a}$ & - & - \\
$\mathrm{BVS}(\mathrm{Fe} 2)$ & $4.12^{b}$ & & \\
\hline
\end{tabular}

${ }^{a}$ The bond valence parameters used in the BVS calculations are adopted from Ref. 24.

${ }^{b}$ The BVS of $\mathrm{Fe} 2$ site was calculated as follows; BVS $(\mathrm{Fe} 2)=0.75 \mathrm{BVS}\left(\mathrm{Fe}^{5+}, r_{0}=1.772\right)+0.25 \mathrm{BVS}\left(\mathrm{Fe}^{3+}, r_{0}=1.751\right)$. 
Table 3. Hyperfine Parameters for $\mathrm{YCu}_{3} \mathrm{Fe}_{4} \mathrm{O}_{12}$ at 290, 100, and $4 \mathrm{~K}$ Deduced from Mössbauer Spectra.

\begin{tabular}{llllll}
\hline Temperature/ K & Species & $I S / \mathrm{mm} \mathrm{s}^{-1}$ & $H F / \mathrm{kOe}$ & $\Delta E_{q} / \mathrm{mm} \mathrm{s}^{-1}$ & Atomic ratio (\%) \\
\hline 290 & $B-\mathrm{Fe}$ & 0.16 & 0 & 0 & 98 \\
& $A^{\prime}-\mathrm{Fe}$ & 0.41 & 0 & 1.75 & 2 \\
\hline 100 & $\mathrm{Fe}^{5+}$ & 0.08 & 208 & 0 & 37 \\
& $\mathrm{Fe}^{3+}(1)$ & 0.33 & 403 & 0 & 12 \\
\hline $\mathrm{Fe}^{3+}(2)$ & 0.43 & 483 & 0 & 36 \\
& $\mathrm{Fe}^{5+}$ & 0.06 & 218 & 0 & 52 \\
$\mathrm{Fe}^{3+}(1)$ & 0.37 & 435 & 0 & 12 \\
\hline $\mathrm{Fe}^{3+}(2)$ & 0.43 & 510 & 0 & \\
\hline
\end{tabular}




\section{CAPTIONS FOR FIGURES}

Figure 1. Crystal structures of cubic perovskites $A \mathrm{Cu}_{3} \mathrm{Fe}_{4} \mathrm{O}_{12}$ with ordered $A$-sites; (a) high-temperature phases $A^{2+} \mathrm{Cu}_{3}^{2+} \mathrm{Fe}^{4+}{ }_{4} \mathrm{O}_{12}$ and $A^{3+} \mathrm{Cu}^{2+}{ }_{3} \mathrm{Fe}^{3.75+}{ }_{4} \mathrm{O}_{12}$, and (b) low-temperature charge-disproportionated phase $\mathrm{Y}^{3+} \mathrm{Cu}^{2+}{ }_{3} \mathrm{Fe}^{3+}{ }_{2}\left(\mathrm{Fe}^{5+}{ }_{1.5} \mathrm{Fe}^{3+}{ }_{0.5}\right) \mathrm{O}_{12}$. Large spheres, pseudo-square planes, and octahedra represent $A$ atoms, $\mathrm{CuO}_{4}$ planar units, and $\mathrm{FeO}_{6}$ octahedral units, respectively.

Figure 2. Observed and calculated SXRD profiles for $\mathrm{YCu}_{3} \mathrm{Fe}_{4} \mathrm{O}_{12}$ at (a) $300 \mathrm{~K}$, and (b) $100 \mathrm{~K}$. The vertical mark indicates the Bragg reflection positions of $\mathrm{YCu}_{3} \mathrm{Fe}_{4} \mathrm{O}_{12}$. Markers and lines indicate observed and calculated profiles, respectively. The bottom curve indicates the difference between observed and calculated profiles. Insets of (a) and (b) show ED patterns for the $[1 \overline{1} 0]$ incidence at 300 and $110 \mathrm{~K}$, respectively. (c) Temperature dependence of the lattice constant $a$ of $\mathrm{YCu}_{3} \mathrm{Fe}_{4} \mathrm{O}_{12}$ and $\mathrm{LaCu}_{3} \mathrm{Fe}_{4} \mathrm{O}_{12}{ }^{15,23}$ (d) Enlarged SXRD profiles between 5 and $15^{\circ}$ collected at 100 and $300 \mathrm{~K}$. The background was subtracted. The intensity was normalized by 220 reflection. The positions of Bragg reflections from charge-ordered $\mathrm{YCu}_{3} \mathrm{Fe}_{4} \mathrm{O}_{12}$ phase (space group $P n \overline{3}$ ) with $h k l$ indices are represented in the bottom. Since the intensities of the $111,112,122$, and 113 reflections are very weak (calculated to less than $0.05 \%$ of the most intense 220 reflection), these are obscured by the background in the SXRD pattern. The Bragg reflections from impurity phases are denoted by inverted triangles.

Figure 3. Mössbauer spectra collected at temperatures between 4 and 290 K. Dotted and solid lines represent observed spectra and fittings, respectively.

Figure 4. (a) Temperature dependence of the magnetic susceptibility of $\mathrm{YCu}_{3} \mathrm{Fe}_{4} \mathrm{O}_{12}$ measured in an external magnetic field of $10 \mathrm{kOe}$ on zero-field cooling (ZFC) and field cooling (FC) between 5 and $300 \mathrm{~K}$. (b) $M-H$ curves measured at various temperatures between 5 and $300 \mathrm{~K}$. (c) Temperature dependence of the electrical resistivity of $\mathrm{YCu}_{3} \mathrm{Fe}_{4} \mathrm{O}_{12}$ between 5 and $300 \mathrm{~K}$.

Figure 5. Soft XAS and MCD spectra of (a) $\mathrm{Fe} L_{2,3}$-edges, and (b) $\mathrm{Cu} L_{2,3}$-edges for $\mathrm{YCu}_{3} \mathrm{Fe}_{4} \mathrm{O}_{12}$ measured in an external field of $19 \mathrm{kOe}$ applied parallel $\left(I_{+}\right)$and antiparallel $\left(I_{-}\right)$to the light propagation axis at $15 \mathrm{~K}$. The MCD intensity was defined by the difference between the two absorption spectra $\left(I_{\mathrm{MCD}}=I_{-}-I_{+}\right)$. XAS spectra are depicted as red $\left(I_{+}\right)$and blue (I-) curves. The curves below show MCD intensity $\left(I_{\mathrm{MCD}}\right)$. 
Figure 6. Arrangements of $\mathrm{Fe}^{3+} / \mathrm{Fe}^{5+}$ ions and magnetic interactions in charge-disproportionated $\mathrm{CaCu}_{3} \mathrm{Fe}_{4} \mathrm{O}_{12}($ left $)$ and $\mathrm{YCu}_{3} \mathrm{Fe}_{4} \mathrm{O}_{12}$ (right) phases. Large filled, small open, and small grey circles represent $\mathrm{Fe}^{3+}, \mathrm{Fe}^{5+}$, and $\mathrm{O}$ ions respectively. Arrows indicate the lengths and up/down states of spin magnetic moments.

Figure 7. Electronic states of $A \mathrm{Cu}_{3} \mathrm{Fe}_{4} \mathrm{O}_{12}\left(A=\mathrm{Ca}^{2+}, \mathrm{Sr}^{2+}, \mathrm{Y}^{3+}\right.$, and $\left.\mathrm{La}^{3+}\right)$ perovskites at low temperature. 

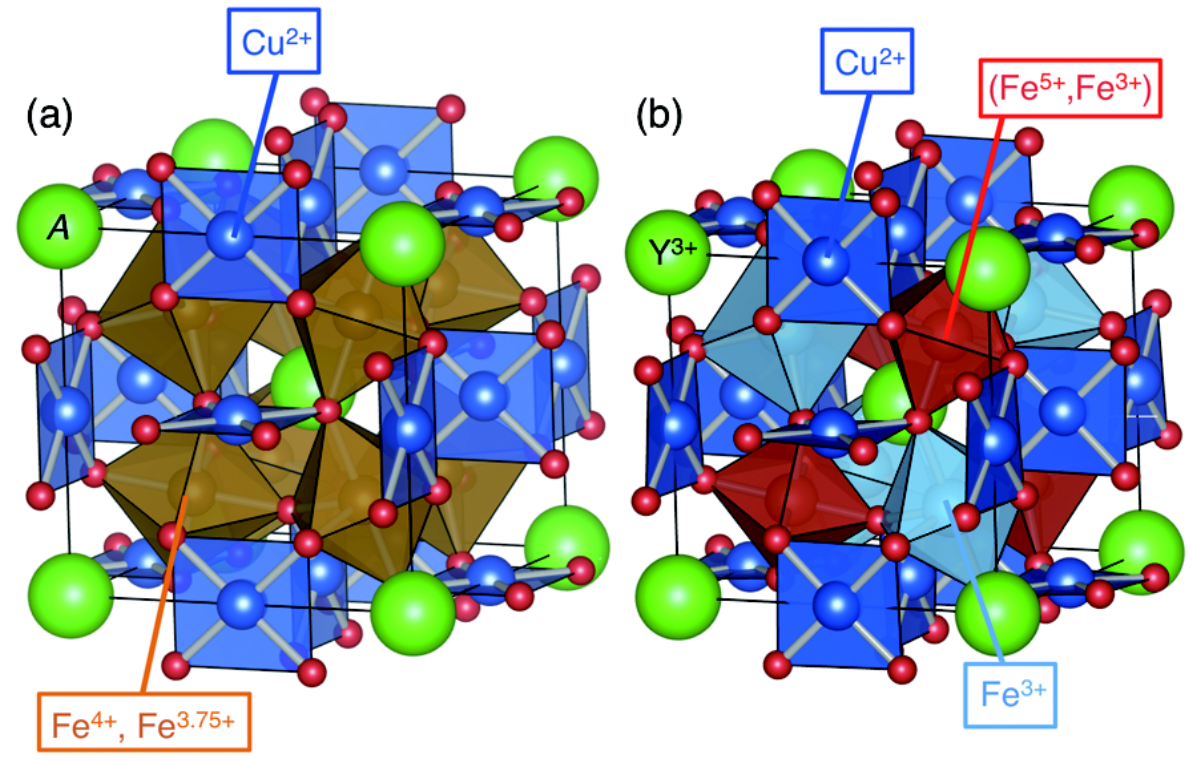

Figure 1 

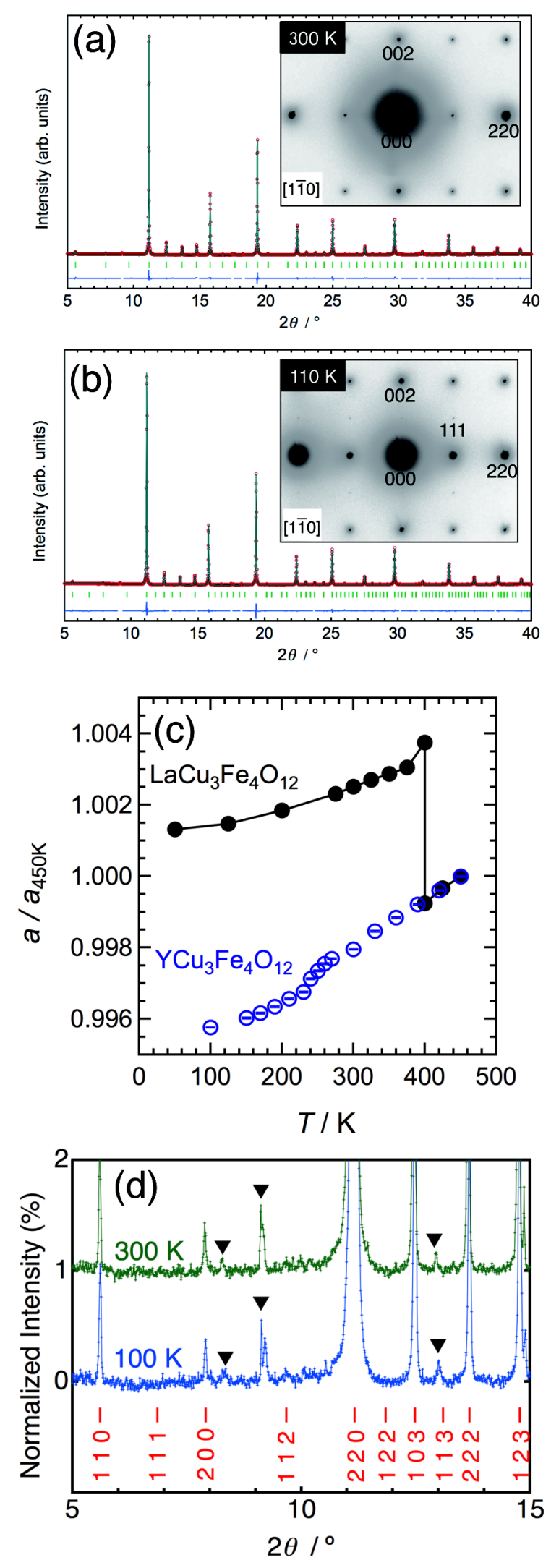

Figure 2 


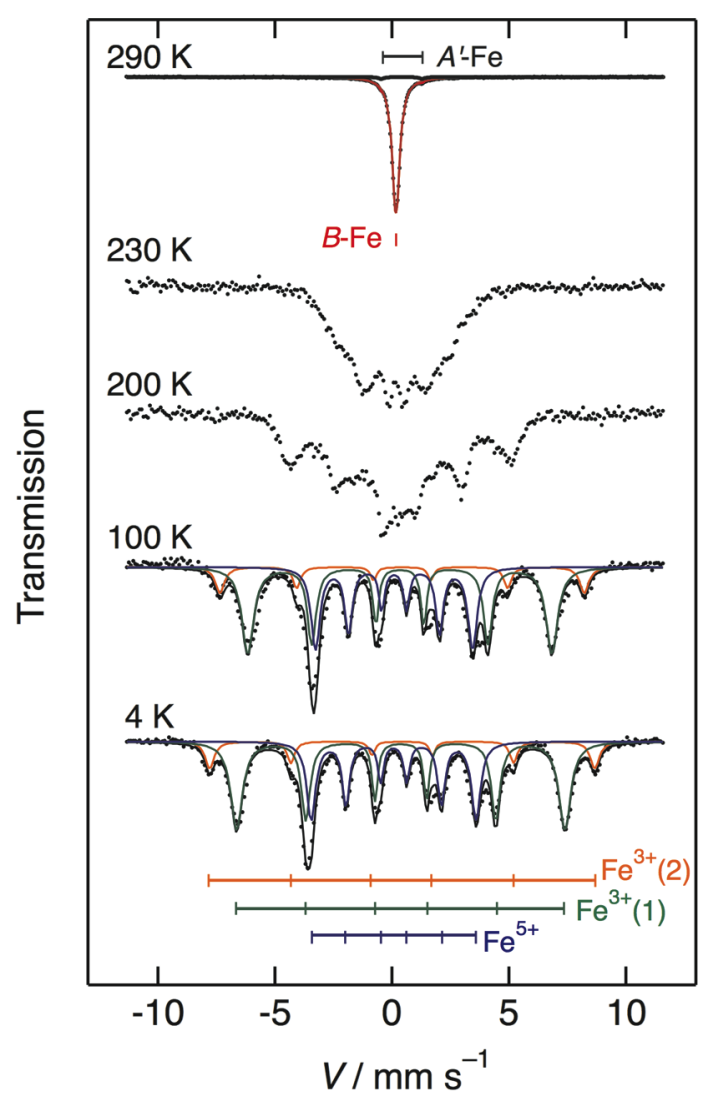

Figure 3 

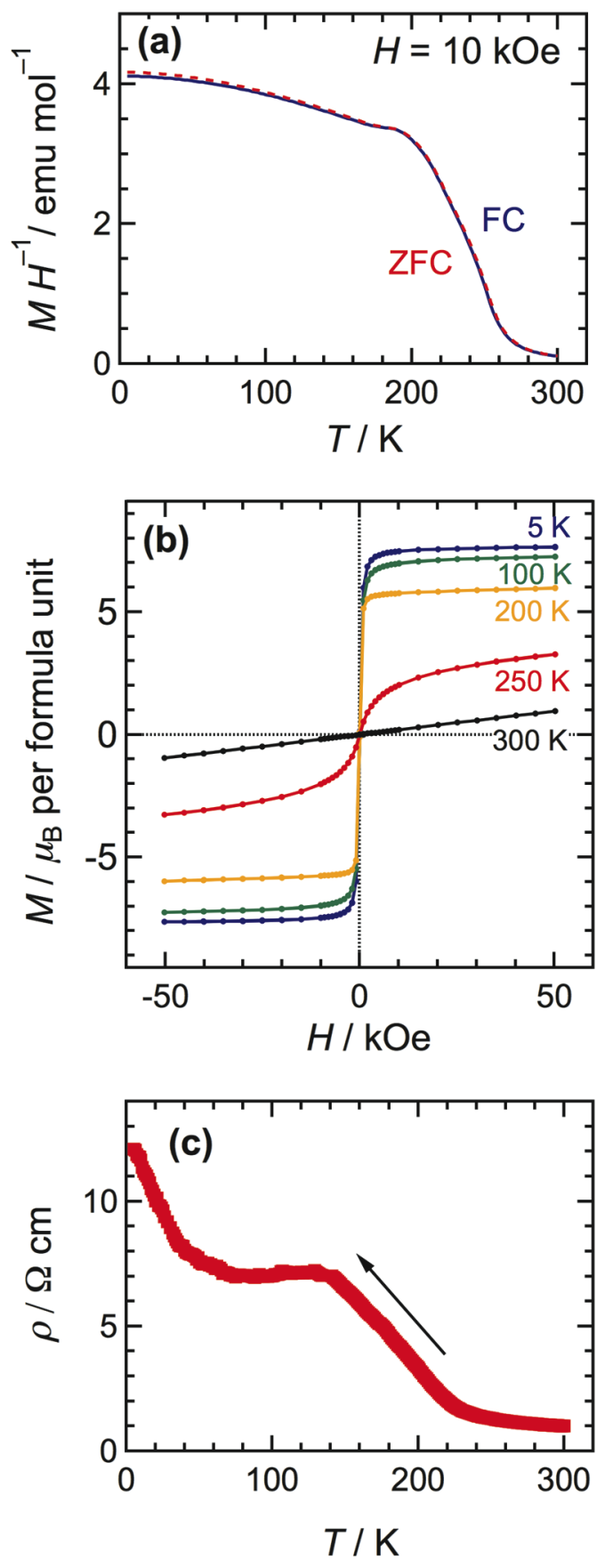

Figure 4 

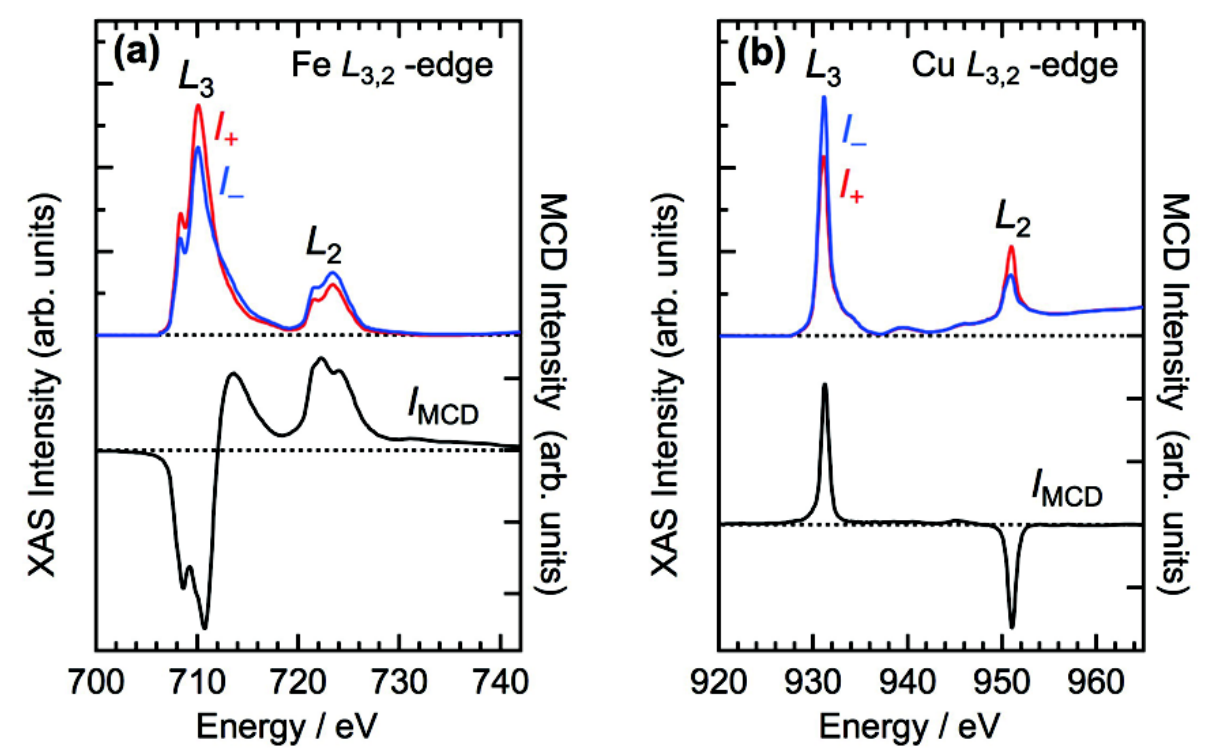

Figure 5

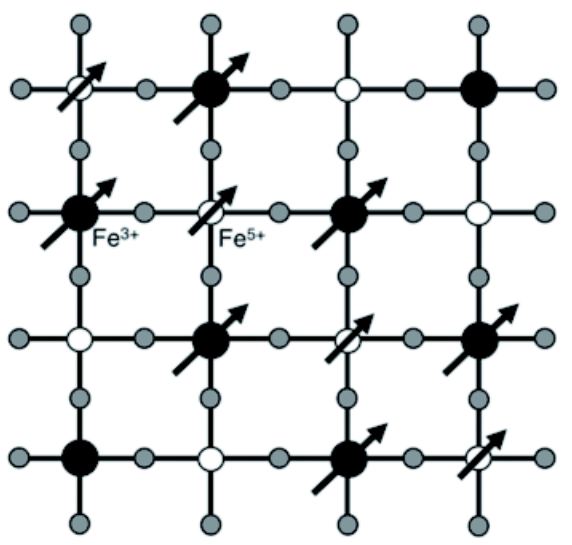

$\mathrm{Fe}^{5+}: \mathrm{Fe}^{3+}=1: 1$

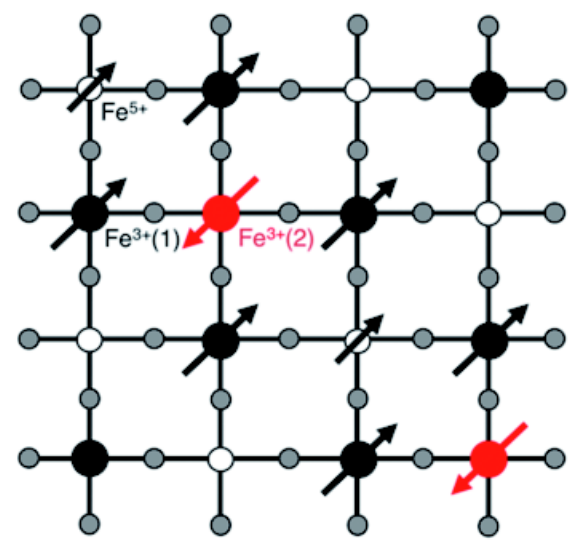

$\mathrm{Fe}^{5+}: \mathrm{Fe}^{3+}=3: 5$

Figure 6 


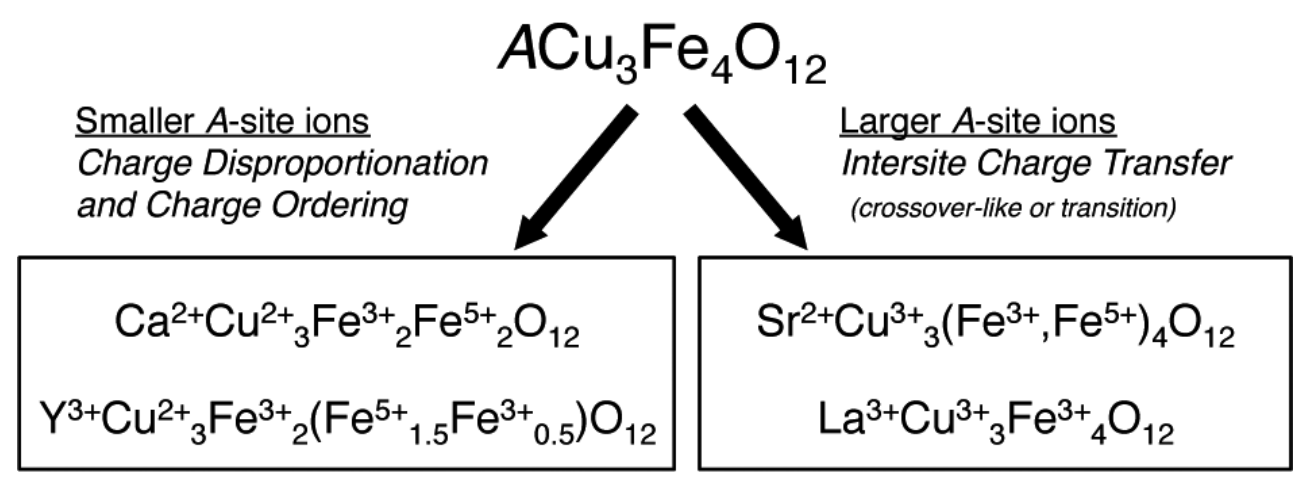

Figure 7

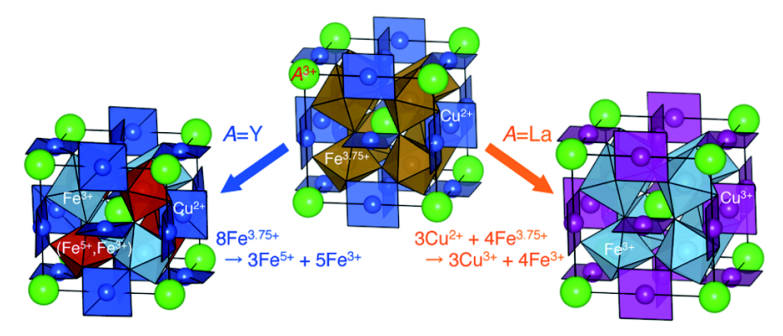

TOC image 